\title{
O aumento das qualificações e o bem-estar intergeracional: O emprego e a produtividade em Pandemia
} Raising qualifications and intergenerational wellbeing:
Employment and productivity in the pandemic

\author{
António Duarte Santos, \\ Universidade Autónoma de Lisboa, Portugal (ajsantos@autonoma.pt)
}

Resumo: Nós humanos não estamos programados para assistir a alterações bruscas e realidades novas que daí advêm, mas a realidade é bastante mais convencional do que as nossas ideias. Isto significa que a realidade pós Covid-19 será mais incerta, propagadora do risco e, logo, do medo e da precaução. É o advento de transformações velozes que nos obrigará a sermos mais humildes perante a natureza, o convívio e o ensino. O mito do digital aumenta algumas qualificações no curto prazo, mas a prazo altera o método da transmissão do conhecimento com reflexos óbvios no modelo de emprego, logo na produtividade e no lazer. Dito de outra forma, esta trilogia a que estamos a assistir seguirá ao longo do tempo o seu rumo adaptativo. Entretanto, esta turbulência já está a criar um fosso entre gerações. Caminhamos num trilho entre o modo de vida presencial e o modo de vida remoto. A adaptação a um novo mercado de trabalho que nos espera continuará a gerar rendimentos sem os quais o viver e o lazer não trarão bem-estar. Os locais de ensino estão a ser reinventados, provocando a familiaridade com as plataformas digitais e com os contactos remotos. Não restarão dúvidas sobre os efeitos teoricamente nefastos sobre as qualificações dos estudantes e sobre a formação contínua de quem labora. Delicadamente tudo mudou. O reflexo da turbulência provocada pela pandemia tornou mais evidente o que já vinha a ser latente, ou seja, acelerou a complementaridade do ciclo de aprendizagem e do conhecimento até ao mercado de trabalho. É o que pretendemos ensaiar com este testemunho.

Palavras-chave: qualificações, bem-estar, gerações, emprego 


\begin{abstract}
We humans are not programmed to witness sudden changes and new realities that come from it, but reality is much more conventional than our ideas. This means that the post-Covid-19 reality will be more uncertain, propagating risk and, therefore, fear and precaution. It is the advent of rapid transformations that will force us to be more humble in the face of nature, coexistence and teaching. The myth of digital increases some qualifications in the short term, but in the long term it changes the method of transmitting knowledge with obvious reflexes on the employment model, therefore on productivity and leisure. In other words, this trilogy that we are watching will follow its adaptive course over time. However, this turmoil is already creating a generation gap. We walk a path between the face-to-face way of life and the remote way of life. Adapting to a new job market that awaits us will continue to generate income without which living and leisure will not bring well-being. Teaching locations are being reinvented, provoking familiarity with digital platforms and remote contacts. There will be no doubt about the theoretically harmful effects on the qualifications of students and on the continuous training of those who work. Gently everything changed. The reflexes of the turmoil caused by the pandemic made what was already latent more evident, that is, it accelerated the complementarity of the learning and knowledge cycle to the job market. This is what we intend to rehearse with this testimony.
\end{abstract}

Keywords: qualifications, wellbeing, generations, job

\title{
1. Introdução na circunferência da pandemia Covid-19
}

À medida que o mundo continua a lidar com as consequências humanas e económicas da Covid-19, as incertezas permanecem, criando um sentimento de permanência no tempo. As epidemias e pandemias refletem-se na cultura geral das sociedades com consequências económicas, políticas e sociais que absorvemos nos momentos ulteriores (Pinto, 2020). As desordens e mutações virais são fenómenos naturais que afetam os humanos. Três fatores determinarão o impacto deste vírus híbrido no mundo real: até que ponto ele pode escapar da imunidade desenvolvida por aqueles que foram vacinados ou previamente infetados por várias variantes, a sua infecciosidade inerente e a gravidade que a doença possa causar. Este enquadramento é indispensável fazê-lo por forma a emoldurar o tema que está desproporcionado nas três áreas em que a sociedade e a elite de um país devem colocar na 
agenda quotidiana: a sustentabilidade económica, a inclusão social e o crescimento económico ou criação de bem-estar (Neves, 2020). Quem não gostaria de ver estas três componentes na economia global? Muitas vezes os decisores políticos veem apenas as compensações entre elas. $\mathrm{Na}$ verdade, há um conjunto de forças ainda mais poderoso que liga esta tripla combinação para criar um círculo vicioso: sustentabilidade $e$ inclusão $e$ crescimento. Tratar estas matérias de forma individual e desconjuntada não produz os efeitos sociais e laborais profundamente desejados por todos. Os empresários, os professores e os decisores políticos, e.g., contribuem para que os desafios económicos sejam bem identificados e possam ser respondidos da melhor forma, fomentando um crescimento económico sustentado e inclusivo, o que, por si só, não chega. "A tarefa não será fácil, até porque agora juntamos às transições digitais e climáticas que já tínhamos iniciado antes de 2020, as dificuldades acrescidas do "pós-pandemia"” (Centeno, 2021). Estamos ainda muito longe de ganhar esta peleja, mais distantes ainda de vencer o conflito. Os confinamentos talvez tenham vindo para continuar com um formato porventura diferente e poderão mesmo estender-se por mais tempo, o que tem criado um ambiente de dúvida nas pessoas que não é salutar. Relaxar seria o pior sintoma neste momento. Os cidadãos em geral podem manter e cumprir, sempre que possível, o teletrabalho, mas para os estudantes a simplicidade desta afirmação não é nada líquida porque aqui se trata da transmissão de aprendizagem e de conhecimento. Este regime é a preparação e o prelúdio para o futuro de muitos humanos, mesmo que, quando olhamos para o nível de tráfego em certos caminhos, eles nos pareçam apenas substitutos, o que não é rigoroso que assim seja. Não esclarecer este desiderato é continuar sempre para além da linha vermelha, com custos para os doentes e opções éticas difíceis de tomar, quando confrontados com o trade-off de quem salvar ou não salvar face à opção a tomar com a Covid-19. Acresce a preocupação dos quadros clínicos que afetam a saúde mental ou sofrimento psicológico, como a ansiedade, a depressão e o esgotamento. A variável tempo é a grande incógnita desta equação. A expressão do latim "natura non facit saltum" traduz isso mesmo, dado o seu significado "a natureza não dá saltos”, que Charles Darwin (1859) já tinha como divisa, frase latina atribuída a Gottfried Wilhelm Leibniz (1646-1716), filósofo e matemático alemão, ou ao naturalista e médico sueco Carl von Lineu (1707-1778). 
Segundo o naturalista inglês, a evolução dá-se por meio de pequenas transformações no decorrer de diversas gerações dos seres vivos, configurando um processo evolutivo lento, mas ininterrupto. A natureza não acompanha os saltos da nossa imaginação, mas reage a esta nossa sobriedade. E os efeitos estão à vista no que diz respeito ao emprego, indicador económico decorrente de sociedades organizadas, e às condições de melhoria da produtividade, componente imprescindível para a melhoria do bem-estar dos cidadãos através da criação prévia de riqueza medida em termos económicos pelo Produto Interno Bruto (PIB). Um relatório da Organização Internacional do Trabalho (OIT, 2022) sobre o futuro do trabalho assevera que as condições de trabalho são essenciais para uma labuta apropriada. Isso é particularmente significativo hoje em dia, pois garantir a segurança e a saúde no trabalho é fundamental na gestão da pandemia e do que gravita à sua volta, com reflexos positivos na segurança mental dos trabalhadores, contribuindo para que as suas aptidões mantenham as atividades económicas viáveis. Não obstante, a ideia normal que subsiste é a distinção entre os gestores e os trabalhadores, mas o princípio do estatuto laboral tem uma natureza mista, ou seja, formam uma unidade com objetivos comuns, como a produtividade e o volume de produção. Estes dois elementos transferem consigo um melhor desempenho do bem-estar social porque existe entre eles uma relação biunívoca.

\section{A metamorfose das qualificações}

O pré-escolar e as escolas básicas dão origem aos criadores do futuro enquanto os ascendentes estão no que é mensurável, como o trabalho. No novo real, e não no novo normal, para as avaliações é importante o ensino presencial, embora persiste a dúvida de que tal seja uma certeza em todas as unidades curriculares do conhecimento. Não há modelo incólume à fraude no que à avaliação diz respeito. Que grandes desafios se colocam ao modelo digital de aprendizagem? Há desafios como o da empatia. O professor já não é um mestre que debita matérias, mas alguém que gere o processo de conhecimento do aluno, e este exige empatia. As plataformas, e.g., Zoom, Teams ou Webex permitem continuar o processo, mas há um elemento que é profundamente relacional e pessoal e que não é substituível pela tecnologia. Nos filmes de ficção científica constrói-se a imagem das tecnologias imersivas ou 
de uma relação com um avatar, mas ainda não estamos lá. As plataformas online são muito mais exigentes para estudantes e professores. A tecnologia continua a ter dois efeitos. O primeiro é suplantar alguns receios que o corpo docente poderia ter relativamente à sua hipotética substituição pela tecnologia. No entanto, não há permuta possível porque são complementares. O segundo tem a ver com o fato de termos de usar a tecnologia como uma oportunidade, sabendo que a componente emocional se perde e tem de ser compensada de outra forma. Como? Uma das formas é alargar o tempo de interação uma a uma, e.g., como as tutorias, ou seja, os break out rooms em espaços mais pequenos. A concentração é essencial e aprendemos muito nos dois anos de pandemia. Não podemos pensar em manter hora e meia, duas ou três horas de conclaves nos mesmos moldes no ensino superior, o que é pior ainda no secundário e no escolar. Temos de encontrar estratégias de reduzir este impacto e aumentar o trabalho de preparação com outros materiais e criar uma componente assíncrona. A migração online trouxe igualmente aspetos positivos na partilha no curto prazo e iniciou a ponte para o futuro, embora com o tormento que cada mudança produz. Estes dois anos fizeram sobressair aquilo a que Kirschner et al. (2017) chamaram de "nativos digitais", com uma tendência para o ensino mais individual sem grande preocupação crítica para a qual os estudantes devem ser preparados. Esta situação tornou-se mais visível pela falta de meios atempados aos estudantes vindos de ambientes mais desfavoráveis, algo que a grande maioria dos Estados não acompanhou devidamente, o que piorou os resultados educativos. As empresas são mais ágeis nesta configuração porque a sua produção não pode parar para que a economia funcione no dia-a-dia e da qual necessitamos ininterruptamente. Estamos e vamos continuar a viver individual e coletivamente em constantes mudanças nos nossos comportamentos. Sobressaem, assim, as qualidades inatas de cada um, as chamadas soft skills. Por outras palavras, a Covid-19 fez-nos interiorizar a importância das pessoas, o valor de cada cidadão e a nobreza de cada trabalhador. A situação pandémica recomenda a vigilância assídua da aprendizagem e do crescimento das hard skills de toda uma geração. As máquinas advindas da tecnologia não podem, por si só, impedir uma realidade que já é essencial ao futuro dos cidadãos, antes devem ser complementares com os ajustamentos mentais a que obrigam. Não só há incapacidade das pequenas e grandes empresas em escalar a 
produção, como o facto de ser cada vez mais frequente a capacidade de captar pessoas de fora com atributos que muitas das empresas detêm nos seus quadros de pessoal e que se tornaram libertáveis. Trata-se de um fenómeno adaptativo catalogado com a nova realidade mutável dos tempos supérfluos em que vivemos. Aqui entramos na esfera dos decisores políticos. As contendas políticas de curto prazo tiveram precedência sobre assuntos de longo prazo e assim irá continuar. Essa é a grande dificuldade de todos os governos e dos decisores políticos, ou seja, conseguirem refletir estrategicamente para além dos limites das legislaturas que são, na realidade, paredes tacanhas. Não é ignorando o que é real que os problemas se dissolvem. O papel da sociedade é trabalhar para que as gerações que virão possam ter mais aptidões em fazer escolhas.

\section{Perda de anos letivos e de qualidade das qualificações?}

Embora estejamos todos a viver num mundo cada vez mais diverso e apreensivo, a segurança das empresas e dos consumidores está a ser retomada de modo distinto, assim como a transformação produtiva está a ser reforçada pela necessidade de uma adaptação revigorada, com reflexo natural no crescimento económico, logo, na criação de riqueza e no fortalecimento do bem-estar. Esta relação tem de ser sustentável, isto é, tem de relacionar a conservação ou a manutenção de um cenário resistente ao longo prazo, de modo a lidar com as sempre prováveis ameaças. As organizações estão a requalificar os seus métodos organizacionais que poderão e irão ter múltiplos efeitos ao nível dos negócios. Mas as organizações funcionam com pessoas e sem elas os restantes fatores de produção, como o capital, a tecnologia e os recursos naturais, nada executam. Trata-se de reconsiderar os modos de produção e dos seus efeitos sobre o volume de negócios, porque é desta cláusula que vêm as remunerações que de imediato se transformam em rendimento disponível para cada agregado familiar. A continuidade das atividades económicas é uma exigência que todos têm de verdadeiramente assumir e interiorizar, o que traz consigo a imposição de organizar cadeias de abastecimento e mudanças do trabalho, seja ele remoto, presencial ou híbrido.

E as vulnerabilidades sociais e profissionais como configurações complementares da produtividade e do lazer? A produtividade do trabalho, imprescindível para 
a criação de bem-estar, corresponde à criação de riqueza anual de um país por trabalhador. O tempo para o lazer, considerado aqui como o tempo que não é utilizado como período de trabalho, também se está a transfigurar. As empresas têm poder discricionário sobre a alocação de tarefas, o que pode prejudicar as perspetivas de carreira dos empregados e, portanto, a sua motivação e gestão do tempo. As atribuições de tarefas e a motivação do trabalhador interagem por meio da extensão da competição no mercado de trabalho, ou seja, a possibilidade de poderem mudar para outra corporação ou de criarem o seu próprio emprego, como seja o empreendorismo. Mais competição aumenta a motivação, mas diminui os incentivos das empresas para designar trabalhadores para tarefas informativas. Uma consequência é que as empresas competitivas bastas vezes escolhem estratégias que levam a uma competição intermediária, o que poderá indiciar uma diminuição da afetação da qualidade das qualificações em algumas zonas de tarefas. Quando o grupo de funcionários é heterogéneo, as organizações podem escolher diferentes práticas de recursos humanos que atraem diferentes tipos de trabalhadores e que se diferenciam pelas oportunidades de carreira que oferecem dentro e fora da empresa (Bar-Isaac et al., 2022). Não quer dizer que as pessoas todas tenham de ir para o desemprego, embora, para algumas, isso seja uma realidade previsível devido à rotação intergeracional, à falta de requalificação de trabalhadores no ativo e a chegada à idade de reforma. Muitas profissões vão ter o seu fim, mas outras vão aparecer, como assim tem sido ao longo da História. Muitas pessoas quererão mudar de emprego, outras tencionarão criar os seus próprios empregos e outras serão abrangidas pelo lay-off ou algo parecido a um prazo curto ou longo, mas não muito distante. Ora, quem está em risco imediato nos próximos meses de abalo da Covid-19 no mercado de trabalho deverá ainda ter alguns anos de apoios públicos e de aperfeiçoamento à nova realidade. Partindo do axioma de subsistência de um regime híbrido do exercício do trabalho, a verificação do modo de execução do trabalho, ou oferta de trabalho, será controlado por cada trabalhador à distância, mas a separação da propriedade dos meios de produção e do abastecimento de mão-de-obra vão permanecer. Podemos até indagar se não estaremos a caminhar para a preponderância do trabalho no domicílio, o que não é novo para ninguém desde há dois anos. Os efeitos 
negativos no emprego ainda serão graves nesta situação de emergência social, económica e financeira. Este cenário de tendência de perdas de emprego à medida que for diminuindo a readaptação terá uma propensão paulatinamente decrescente acompanhada de uma maior proteção social (PROSPER, 2021). Um caso cada vez mais evidente em todos os países é o número crescente dos problemas relacionados com a saúde mental. É um termo usado para descrever o nível de qualidade de vida cognitiva ou emocional. Pode incluir a capacidade de um indivíduo otimizar a sua vida pessoal ou agregada e encontrar um equilíbrio entre as atividades e os esforços para alcançar a sua resiliência psicológica. Esses pontos podem ser esmiuçados em estudos futuros. Não obstante, um efeito indiscutível da pandemia é que forçou as empresas a inovar rapidamente para se adaptarem aos desafios sem precedentes que estão a afetar as suas atividades. $\mathrm{O}$ encerramento de escritórios para proteger a saúde dos funcionários, a mudança radical dos requisitos dos clientes e as interrupções incapacitantes da cadeia de suprimentos têm exigido tomadas de decisão ágeis e soluções criativas. No entanto, a criatividade em reação a uma crise e a construção de uma verdadeira cultura de inovação são duas coisas diferentes. As organizações que se vão preparando para o novo real, que não o novo normal (Santos, 2020) desejam incorporar criatividade e inovação sustentáveis na sua cultura. O mesmo é dizer que as qualificações adaptáveis aos modelos de trabalho exigem pessoas com capacidade e gestão de prioridades, adaptabilidade, pensamento crítico, iniciativa e empatia. Como estas competências são cada vez mais valorizadas e procuradas, elas serão a coluna vertebral do sucesso. Se as soft skills são difíceis de identificar, as hard skills têm vindo a perder terreno devido ao modelo de ensino remoto que tem sido utilizado no ensino em geral e na transmissão de conhecimento em particular. Para Crato (2020: 187-188) “Temas mais conceptuais são menos prejudicados do que capacidades mais dependentes de uma prática continuada”. As capacidades de escrita e de cálculos sofrem mais com este estilo de ensino. Com o ensino remoto, em que hoje se constatam mudanças assimiladas pelas pessoas, prevê-se que a principal mudança seja ou venha a ser a transição de um modelo de "sempre assim" e não do "isto vai passar". Num estudo respeitante aos Estados Unidos, os estudantes que passam para os anos letivos seguintes vão despreparados e estão a perder os 
principais blocos de construção do conhecimento que são necessários para o sucesso, enquanto os alunos que repetem um ano têm muito menos probabilidade de concluir o ensino médio e passar para a faculdade (Dorn et al., 2021). É aqui que se estão a formar as competências técnicas com consequências imprevisíveis, e.g., a um prazo de vinte anos, conforme previsto, e.g., no Plano de Recuperação e Resiliência (PRR) de Portugal, isto é, um prazo que vai exigir um esforço enorme e gradual da população adulta com qualificações médias até 2041 e da população com qualificações elevadas no mesmo período de tempo. Deste modo, haverá uma oscilação da população com baixas qualificações que irão transitar para níveis de qualificação e especialização mais baixos. De acordo com Simões et al. (2021, p. 105), "o aumento da produtividade deverá resultar da entrada de trabalhadores mais qualificados e mais eficientes no mercado de bens finais, mas também do estímulo ao conhecimento e inovação que se traduz em novos bens, empresas elou métodos de produção". Vejamos um exemplo português sintetizado e retratado no Quadro 1, que tem por base o estudo publicado pelo Gabinete de Planeamento, Estratégia, Avaliação e Relações Internacionais (GPEARI) do Ministério das Finanças e do Gabinete de Estratégia e Estudos (GEE) do Ministério da Economia. Mostra a evolução esperada da população portuguesa com três tipos de qualificações, a saber, baixas, médias e altas, até 2041, em percentagem da população em idade ativa. Segundo o estudo mencionado, "Este impacto resulta de um aumento gradual de cerca de 1 p.p. na proporção de população adulta com qualificações médias até 2041, ...e de cerca de 0.1 p.p. na proporção de população com qualificações altas ...no mesmo período". Indiretamente prevê-se uma variante da população com baixas qualificações de $-1,1 \%$, "que resulta da transição de indivíduos do nível de qualificação baixo para médio, e da transição dos indivíduos do nível de qualificação médio para alto". Ainda de acordo com as medidas de educação previstas no PRR, elas refletem-se em 20 anos "num aumento do PIB potencial de 0,8\% decorrente de um aumento da Produtividade Total dos Fatores de Produção de 0,5\% e do emprego de 0,3\%". Será suficiente? Fica a resposta para todos à medida que a realidade evoluir e for sendo monitorizada. 
Quadro 1 -Evolução esperada da população com qualificações baixas, médias e altas

(\% população em idade ativa), crescimento acumulado

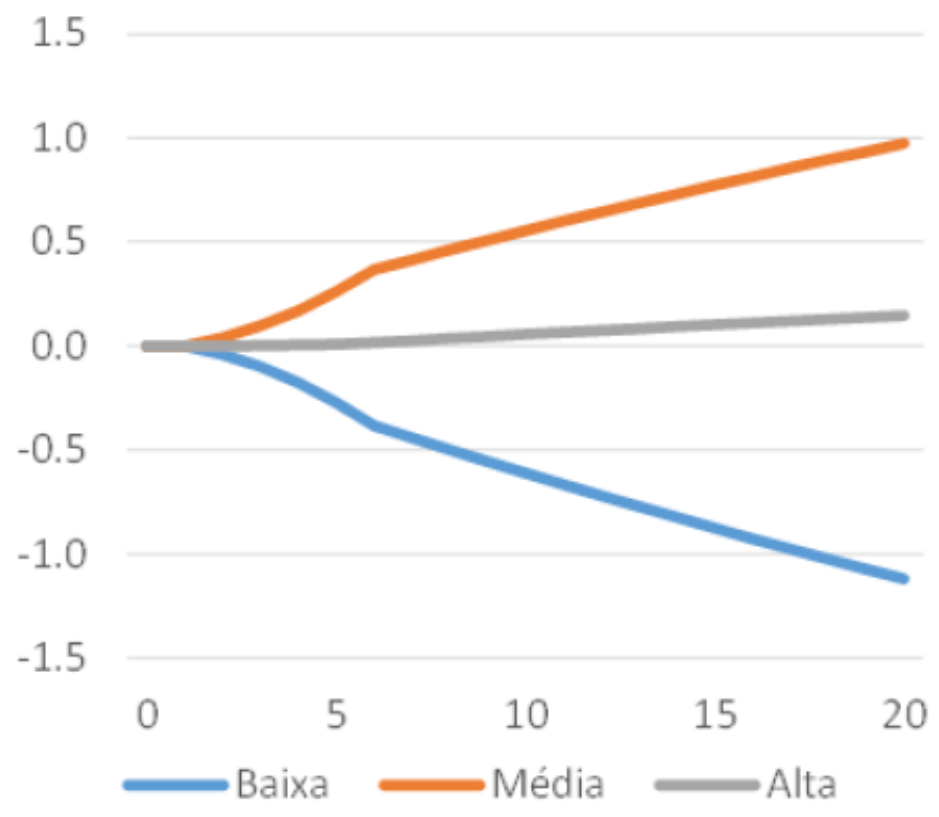

Fonte: Simões et al. (2021:110).

O caso português, apesar de aqui evidenciado, não é distinto dos outros países no que à sua essência diz respeito. A dúvida da substância permanece em todos os países. Poderá acontecer que tudo isto seja o reflexo de assimetrias de qualificações, como se de anos perdidos na formação se tratassem, onde vai sobressair o individualismo, o isolamento e mais egoísmo num ambiente impessoal e inconstante. No entretanto, um alerta se impõe, porque só a experiência e as capacidades inatas de cada um, empregado ou não, pode fornecer uma componente crucial de cultura de inovação, em que os gestores incentivam os funcionários a alavancar os seus pontos fortes individuais para emanciparem a sua criatividade e implementarem soluções inovadoras para as dificuldades persistentes. Mesmo antes da pandemia, os países estavam no início latente de uma caminhada com destino a uma "e-economy" (Ross, 2016, p. 13), a qual assenta na inovação coletiva do sucesso. Os cidadãos e as redes de cidadãos estão a capacitar-se para desafiar a situação ex-post da pandemia com capacidades que nunca antes imaginaram que possuíam e podiam aplicar. 


\section{O efeito intergeracional emergente}

A transmissão intergeracional e os seus efeitos permanentes aludem à transferência da condição social e económica entre gerações. Essas transferências entre gerações ocorrem através de uma variedade de meios, incluindo a herança do padrão ocupacional, do nível de escolaridade, dos rendimentos e, finalmente, da riqueza relativa. Os mecanismos de transmissão intergeracional, oriundos da psicopatologia e do comportamento genealogista, envolve processos recíprocos em que a ascendência é um instrumento relevante na transmissão da psicopatologia e viceversa. Essa transmissão entre gerações descreve a continuidade intergeracional dentro e entre comportamentos e características de cada pessoa. Esse ambiente compartilhado envolve um contexto familiar e caseiro mais amplo, como fatores socioeconómicos, caos doméstico e fatores culturais (Deater-Deckard, 2014). As partes empenhadas que os subscrevem vinculam-se, de algum modo, a respeitarem o passado e a projetarem no futuro, quer os compromissos herdados do passado, quer os fins prosseguidos e a prosseguir pelo esforço comum ao longo do tempo. Autorregular a fisiologia, as cognições, as emoções e os comportamentos em resposta a mudanças na nossa própria condição existencial e num ambiente dinâmico é, além de trabalhoso, penoso e resiliente porque transporta anos de crescimento e experiências acumuladas no que diz respeito ao desenvolvimento das capacidades de realização consistente da própria autorregulação. Passando de pessoas para as organizações, a realidade mostra diferenças entre as empresas dentro de cada sector. Em todos os sectores algumas empresas suplantam outras, e as empresas que investem mais em intangíveis, como o capital humano, são as mais produtivos porque a vantagem competitiva está ancorada no conhecimento temporalmente armazenado. Becker (1994, p. 11) definiu o conceito de capital humano como as "atividades que influenciam o futuro monetário e o rendimento físico aumentando os recursos das pessoas". Maior investimento neste ativo intangível torna os produtores mais propensos a criar novas formas de vantagens comparativas e a conceber uma trajetória para a transição entre as gerações atuais e as futuras. Trata-se de uma evolução de experiências passadas com conhecimentos novos. Isso indica que a amplitude do investimento em intangíveis humanos promove a resiliência, na justa medida em que produz efeitos positivos sobre a criação de riqueza para um desejável bem-estar 
sustentável. Em síntese, o investimento em capital humano gera um melhor retorno sobre o investimento, quer no digital, quer no analítico.

No entanto, esta exposição envolve um devaneio em que algumas evidências sugerem que a mobilidade intergeracional é dignamente limitada porque nem sempre os resultados transmitidos entre gerações são assim tão claros. Uma teoria que tem recebido muita atenção é a explicação do capital humano, desenvolvida por Becker et al. (1979). O capital humano adquirido pelas crianças afeta muito os resultados dos seus desempenhos e, por esse facto, esse capital é deveras afetado pelas escolhas de investimento feitas pelos agregados familiares "maximizadores da sua própria utilidade” usando o propósito de Schumpeter. Dado um conjunto limitado de recursos, e.g., tempo, rendimento, lazer, bens tangíveis, os pais prosseguirão a sua propensão para investir os seus recursos disponíveis nos filhos até que a sua taxa de retorno esperada, concentrada na capacidade e no potencial de ganhos de uma criança ou jovem, não seja melhor do que a taxa marginal de retorno dos mercados de capitais, ou seja, a taxa de juro dos mercados financeiros ou a eficiência marginal do capital, no dizer de Keynes em 1936 com a publicação da sua obra Teoria Geral do Emprego, do Juro e da Moeda. Certas implicações desta conjetura podem ser expostas de dois modos. Em primeiro lugar, (1) sendo os recursos limitados, os níveis de investimento numa criança serão determinados pelas suas aptidões, e (2) a presença de restrições de crédito, sobretudo em famílias de baixos rendimentos, levam a reduções nos benefícios para as crianças e, rapidamente, a uma menor mobilidade intergeracional. Porém, pesando as duas exposições, a tendência é para ser mais evidente a análise de Becker que, na globalidade da sua análise, sustenta as provas de comparações entre países. Países com altos níveis de subsídios educacionais e, portanto, níveis mais baixos de restrições de crédito tendem a estar associados a uma maior mobilidade de rendimentos entre gerações. As comparações entre países são difíceis, dada a variedade de justificações alternativas quanto às suas diferenças devido à proeminência que se nota sobre a explicação de que o investimento em capital humano é misto, isto é, pode basear-se em recursos próprios ou apoiar-se em recursos alheios.

Até ao final de 2021, a evidência da magnitude sem precedentes da crise educacional infligida pela pandemia do Covid-19 era indubitável, segundo o Banco 
Mundial (2020), a UNESCO e a UNICEF. No relatório conjunto destas instituições sobre o estado da crise educacional, foram atualizadas as estimativas dos custos económicos das perdas da aprendizagem. A geração, ou "gerações secantes”, deverá desperdiçar US\$ 17 triliões em ganhos ao longo da vida (valor atual) ou cerca de $14 \%$ do PIB mundial de hoje, devido ao encerramento de escolas relacionadas à pandemia da Covid-19 e aos choques económicos e financeiros daí advindos. Essa nova projeção excede em muito as estimativas de US\$ 10 triliões divulgados em 2020. Acresce que em países de baixo e médio rendimento, a proporção de crianças que vivem em carência de aprendizagem, já 53\% antes da pandemia, pode chegar a $70 \%$ devido aos confinamentos que atingem os estabelecimentos de ensino e a ineficácia dos estudantes em modo remoto poderem garantir a continuidade da aprendizagem, essencialmente para as crianças. Os dados mais recentes também apontam para uma devastação de desigualdades na formação entre gerações e grupos socioeconómicos, locais e entre países.

Uma segunda explicação social e económica para a insistência na imobilidade intergeracional é a transferência de riqueza cumulativa sob a forma de heranças e poupanças. Essa explicação tem recebido pouca atenção devido à falta de dados estatísticos sobre os que atingiram a idade em que as heranças e as poupanças são normalmente repassadas provavelmente devido ao prolongamento da esperança de vida (Piketty, 2014, p. 566). Ao estudar os registos de óbitos de um conjunto de residentes muito ricos do Estado do Connecticut e seus filhos, Paul Menchik (1979) encontrou uma elasticidade intergeracional de 0,69 entre a riqueza dos filhos e dos pais no momento da morte. Esse descobrimento sugere que as heranças são altamente importantes para a extremidade superior da distribuição do rendimento. No entanto, muitos dos atentos descartaram amplamente a riqueza como um fator importante na persistência geral intergeracional dos resultados, porque a maioria das famílias não transmite heranças substanciais. Por exemplo, de acordo com Gary Becker e Casey Mulligan (1997), apenas 2 a 4 por cento das propriedades transmitidas por morte nos Estados Unidos entre 1960 e 1995 estavam sujeitas a impostos sobre herança (Martin-Matthews et al., 2018). Porém, surgiram outras visões e análises inovadoras de outros tantos autores, onde sobressaíram Bengston et al. (1985) com o conceito de "solidariedade ou coesão familiar". Devido a isso, tem esse 
ponto de vista analítico e empírico sido objecto de investigação intergeracional desde então. Na lógica e sustentação dos autores, esse conceito é alicerçado teoricamente na perpectiva do curso de vida dos cidadãos, concentrando-se em seis dimensões da solidariedade: a) na estrutura do agregado familiar; b) na solidariedade associativa, isto é, o grau em que os membros de uma linhagem estão em contato uns com os outros e se envolvem em comportamentos compartilhados ou atividades comuns; c) na solidariedade afetiva, ou seja, o estado de sentimento positivo expresso na relação intergeracional; d) na solidariedade consensual, que é a posição de consenso ou conflito em crenças ou orientações externas ao agregado familiar; d) na solidariedade funcional, que não é mais do que o grau em que a assistência financeira e as trocas de serviços ocorrem entre os membros do agregado familiar; e) na solidariedade normativa, que procura representar as normas familiares mantidas pelos membros do agregado familiar em termos de expectativas de proximidade e assistência.

\section{Conclusões}

Desde logo, constatamos, em face do que ficou patenteado, que muito há a expor e a investigar sobre o tema das qualificações e da transmissão intergeracional do bem-estar individual e social. No caso do capital humano, esta pesquisa infundiu vários desses campos aplicados, com ênfase particular na administração do trabalho, na economia da educação, na economia do crescimento, na economia do desenvolvimento, na economia doméstica e na economia da saúde. Além disso, ao dar ao capital humano um conteúdo mais amplo e vago, contribuiu de certa forma para promover a sua circulação e tendência para a mobilidade, principalmente por fazer parte da gíria científica, económica e política e ajudar a erodir as resistências à sua abordagem. As pessoas em idade ativa estão a tornar-se cada vez mais numa estrutura para entender vários aspectos do comportamento humano, fornecendo exemplos eficazes e poderosos da capacidade das Ciências Sociais para lidar com uma miríade de questões da sociedade. Para que isso se tornasse exequível, as bases intelectuais e pessoais estabelecidas em ambiente de pandemia foram desempenhos essenciais. A enfermidade da Covid-19 causou uma situação adversa e de perturbação generalizada da atividade empresarial, logo laboral, em todo o mundo, mas os 
efeitos nefastos de adaptação foram bastante desiguais e erraticamente compensados por causa de falhas nas qualificações e nas suas adequações ao novo real. As descidas no nível de bem-estar foram o reflexo último desta turbulência. A evidência por nós redigida procurou elevar e ressalvar o papel de medidas importantes quanto à preservação da capacidade produtiva instalada e do emprego. A salvaguarda destas condições assume particular relevância porque contribui para acelerar a recuperação e mitigar os impactos de longo prazo da pandemia quanto ao nível de vida comum de todos os cidadãos.

\section{Referências}

Banco Mundial (2020, junho 18). Simulation the Potential Impacts of Covid-19 School Closures on Schooling and Learning Outcomes: a Set of Global Estimates. The World Bank. https://bit.ly/34lBhkr

Bar-Isaac, H., \& Levy, R. (2022). Motivating employees through career paths. Journal of Labor Economics, 40(1), 95-131. https://doi.org/10.1086/713759

Becker, G. S., \& Tomes, N. (1979). An equilibrium theory of the distribution of income and intergenerational mobility. Journal of political Economy, 87(6), 1153-1189. https://doi.org/10.1086/260831

Becker, Gary (1994). Human Capital: A Theoretical and Empirical Analysis, with Special Reference to Education. University of Chicago Press, Chicago.

Becker, Gary S. (2009). Human capital: A theoretical and empirical analysis, with special reference to education. University of Chicago press.

Becker, G. S., Mulligan, C. B. (1997). The Endogenous Determination of Time Preference, The Quarterly Journal of Economics, 112(3), 729-758. https://doi.org/10.1162/003355397555334

Bengtson, V. L., \& Silverstein, M. (2019). Longitudinal study of generations, California, 1971, 1985, 1988, 1991, 1994, 1997, 2000, 2005 [Data file and codebook]. https://doi.org/10.3886/ICPSR22100.v5

Centeno, M. (2021, novembro 29). Os desafios da economia portuguesa na pós-pandemia. Intervenção de abertura do Governador do Banco de Portugal na Conferência do Expresso e Banco de Portugal. Banco de Portugal. https://bit.ly/342DMsf

Crato, N. (2020). Como a pandemia mudou a educação, e como a pandemia não mudou a educação. In N. Santos (Org.). Pensar o Futuro: Portugal e o mundo depois da Covid-19 (pp. 183-197). Porto Editora. 
Darwin, C. (1859). A Origem das Espécies. Lello \& Irmão Editores. Porto. S/d.

Deater-Deckard, K. (2014). Family Matters: Intergenerational and Interpersonal Processes of Executive Function and Attentive Behavior. Current Directions in Psychological Science, 23(3), 230-236. https://doi.org/10.1177\%2F0963721414531597

Dorn, E., Hancock B., Sarakatsannis, J., \& Viruleg, E. (2021). COVID-19 and education: The lingering effects of unfinished learning. Mckinsey \& Company. https://mck.co/3rUxjYk

Kirschner, P. A., \& De Bruyckere, P. (2017). The myths of the digital native and the multitasker. Teaching and Teacher Education, 67, 135-142. https://doi.org/10.1016/j.tate.2017.06.001

Martin-Matthews, A., \& Kobayashi, K. M. (2018). Intergenerational Transmission: Research on Levels of Intergenerational Mobility. In International Encyclopedia of the Social Sciences, May 29, https://bit.ly/3o8tY6O

Menchik, P. L. (1979). Inter-generational Transmission of Inequality: An Empirical Study of Wealth Mobility. Economica, 46(184), 349-362. https://doi.org/10.2307/2553676.

Neves, J. C. (2020). Economia: o vírus não dá saltos. In N. Santos (Org.), Pensar o Futuro: Portugal e o mundo depois da Covid-19 (pp. 123-137). Porto Editora.

OIT, Organização Internacional do Trabalho (2022). World Employment and Social Outlook: Trends 2022. Genebra.

Piketty, T. (2014). O Capital no século XXI. Temas e Debates.

Pinto, J. N. (2020). Contágios - 2500 anos de Pestes. Publicações Dom Quixote.

PROSPER - Católica Lisbon Center of Economics for Prosperity (2021, junho 22). 400 Mil novos pobres e $9 \%$ de aumento na desigualdade devido à covid-19 em Portugal. Universidade Católica Portuguesa, Notícias. https://bit.ly/3KY6X0q

Ross, A, (2016). As Indústrias do Futuro. Conjuntura Actual Editora.

Santos, A. D. (2020). A crise estabelecida e a aversão ao estranho: o novo despertar da vivência racional. Nova Águia, Revista de Cultura para o Século XXI, 26, 93-98.

Simões, M., Fonte-Santa, S. (2021). Efeito das políticas da educação na produtividade. GPEARI, Boletim Mensal de Economia Portuguesa, 12, 105-118. https://bit.ly/3ILSSkC 